\title{
Mental Health Issues and Complex Experiences of Abuse Among Trans and Gender Diverse Young People: Findings from Trans Pathways
}

\author{
Penelope Strauss, MPH, ${ }^{1,2}$ Angus Cook, MBChB, PhD, MBiostats, GradDipHIthEcon, ${ }^{2}$ \\ Sam Winter, PGDE, MEd, PhD, ${ }^{3}$ Vanessa Watson, MClinPsych, ${ }^{4}$ Dani Wright Toussaint, ${ }^{1}$ and Ashleigh Lin, PhD $^{1}$
}

\begin{abstract}
Purpose: Trans and gender diverse (TGD) young people have reported high levels of mental distress in research studies, specifically depression, anxiety, self-harming, and suicidal behaviors. Rates of abuse are also high in TGD populations, but little is known about how this relates to mental health in populations of TGD young people. This study sought to examine associations between experiences of abuse and mental health outcomes.

Methods: A cross-sectional study design was used. An anonymous online questionnaire was conducted to determine rates of abuse among Australian TGD young people $(N=859)$ and the potential association with poor mental health. Primary outcomes of interest were self-reported psychiatric diagnoses, self-harm and suicidal behaviors, and current anxiety and depressive symptoms.

Results: Exposures to six forms of abuse are reported in this article: extrafamilial physical abuse, familial physical abuse, extrafamilial sexual abuse, familial sexual abuse, abuse within an intimate relationship, and other familial abuse (including emotional or verbal abuse and neglect). All six forms of abuse measured were associated with poor mental health overall; risk estimates for some forms of abuse were much stronger than others.

Conclusion: The current findings have wide-ranging implications for clinical practice. Those working in TGD health care need to be aware of the high prevalence of violence and abuse among TGD young people and the association with poor mental health outcomes. The findings also have implications for broader societal change and interventions targeting increasing parental support to reduce familial violence against TGD young people.
\end{abstract}

Keywords: abuse, LGBT, suicide, transgender, trauma

\section{Introduction}

T RANS AND GENDER DIVERSE (TGD)* people have a gender that is incongruent with their sex assigned at birth. Between $1.2 \%$ and $2.7 \%^{2}$ of adolescents are estimated to identify as TGD. TGD young people experience mental health problems at a far higher rate than the general young person population. ${ }^{2-4}$ We have shown that TGD young people report high levels of mental distress, including self-harming (79.7\%), suicidal thoughts $(82.4 \%)$, and attempting suicide $(48.1 \%) .{ }^{5}$ In addition, TGD young people are very likely to have been diagnosed with depression and/or anxiety at some stage in their lives (74.6\% and $72.2 \%$, respectively). ${ }^{5}$
TGD people are more likely to experience violence than their cisgender peers, ${ }^{6}$ placing them at higher risk for developing post-traumatic stress disorder (PTSD), engaging in high-risk behaviors, and suicidality. ${ }^{7}$ The 2015 U.S. transgender survey report indicates that $47 \%$ of transgender adults have been sexually assaulted, $10 \%$ have experienced family violence, and $54 \%$ have experienced intimate partner violence. ${ }^{8}$ A recent study showed that $72 \%$ of transgender and gender nonconforming adults have experienced at least one incident of violence from an intimate partner in their lifetime (32\% reporting sexual violence, $71 \%$ psychological violence, $42 \%$ physical violence, and $29 \%$ assault and injury). ${ }^{9}$

\footnotetext{
${ }^{1}$ Telethon Kids Institute, The University of Western Australia, Perth, Australia.

${ }^{2}$ School of Population and Global Health, The University of Western Australia, Perth, Australia.

${ }^{3}$ School of Public Health, Curtin University, Perth, Australia.

${ }^{4}$ Youth Mental Health, North Metropolitan Health Service, Western Australia Department of Health, Perth, Australia.

*We primarily use the term trans and gender diverse within this article, but when referring to other research, we have reflected the terminology used within the specific article referenced, for example, transgender, gender nonconforming.
} 
Comparatively less is known about the experience of abuse and violence in younger trans populations, with most of the literature focused on the experience of bullying, harassment, and victimization in the school setting. For example, Grant et al. ${ }^{10}$ found that $78 \%$ of transgender adults recalled harassment and 35\% recalled physical assault during their school years. In Australia, 21\% of TGD young people have reported physical abuse because of their gender ${ }^{11}$ and $74 \%$ have reported being bullied. ${ }^{12}$ A large study of university students in the United States (mean age 22.22 years, standard deviation $[\mathrm{SD}]=6.08)^{6}$ showed that transgender students were more likely to experience all types of victimization compared with cisgender students. These include intimate partner violence, stalking, sexual violence, and other physical or verbal violence.

There is surprisingly little exploration of exposure to abuse and violence and poor mental health outcomes among TGD people of any age. Testa et al. ${ }^{13}$ found that transgender adults exposed to physical and/or sexual violence were more likely to have attempted suicide than respondents without this exposure. In addition, sexual violence was associated with increased alcohol and illicit drug use among transgender women. ${ }^{13}$ In a sample of college students, heavy drinking episodes were more likely among transgender individuals who had been verbally threatened or sexually assaulted. ${ }^{14}$ Henry et al. ${ }^{9}$ demonstrated that all types of intimate partner violence (psychological, sexual, and physical) were associated with clinically significant anxiety in a sample of transgender and gender nonconforming adults and all kinds of intimate partner violence (with the exception of physical violence) were associated with clinical depression. Other research has demonstrated that earlier gender-related victimization or trauma (recall of early and late adolescence and, to a lesser extent, early adulthood) was strongly associated with contemporary major depression and suicide. ${ }^{15}$

Much of the previous literature has focused on the experiences of trans women, rarely including trans men and nonbinary individuals; information is needed to explore the experiences of abuse across these different identities. Moreover, comprehensive information is needed on experiences of trauma and mental health outcomes among TGD young people. Using data from the Trans Pathways survey, ${ }^{12}$ the primary aims of this article were to (1) ascertain the prevalence of physical and sexual abuse (both within and external to the family), abuse within intimate relationships, and any other forms of familial abuse experienced by TGD young people; (2) explore relationships of these experiences of abuse with gender identity, sex assigned at birth, and age; and (3) determine the association between the various types of abuse and mental health outcomes.

\section{Methods}

\section{Study design}

A cross-sectional study design was used. An anonymous, online self-reported questionnaire was conducted in 2016. Eligible participants were TGD young people aged 14-25 years who were residing in Australia at the time of the survey. Participants were recruited widely using social media, gender clinics, youth mental health services, support groups, and word of mouth.

\section{Development of the online questionnaire}

Focus groups were held before the study with TGD young people and parents of TGD young people to shape the survey design. The focus group members identified potential drivers of poor mental health (including deciding on the six specific forms of abuse presented in this article) and protective factors for good mental health based on their own experiences and awareness of concerns raised within the community. Qualtrics online survey software (Qualtrics, Provo, UT) was used to construct and host the questionnaire, utilizing branch, display, and skip logic based on participant responses. Responses were collected using Qualtrics from February through August 2016. All survey questions were optional, except those used to determine eligibility (i.e., TGD identification, age, and place of residence). Participants received a participant information form and consented to the study online. Parental consent was waived for this study. The study was approved by The University of Western Australia ethics committee (RA/4/1/7958).

\section{Gender identity and sex assigned at birth}

Participants were asked for both their sex assigned at birth (male/female) and gender identity (open text box). Gender identities were collapsed into categories of male/trans male, female/trans female, nonbinary, and other for the sake of succinctness in this article. Further details on the range of gender identities held by the participants are available in the study by Strauss et al. ${ }^{12}$

\section{Current psychopathology}

Depressive symptoms were indexed on the Patient Health Questionnaire for Adolescents (PHQ-A). ${ }^{16}$ The PHQ-A is a 9-item scale that is scored from 0 to 27 and can be categorized into no depressive disorder (0-4); possible mild depressive disorder (5-9); possible moderate depressive disorder (10-14); possible moderately severe depressive disorder (15-19); and possible severe depressive disorder (20-27). ${ }^{16}$ Anxiety was measured using the Generalized Anxiety Disorder 7-Item Scale (GAD-7). ${ }^{17}$ The categories for the GAD-7 are based on scores suggestive of GAD $(\geq 5)$; moderate to severe anxiety $(\geq 10)$; and severe anxiety $(\geq 15) .{ }^{17}$

\section{Self-reported psychiatric diagnoses}

A range of psychiatric diagnoses (depression, anxiety disorders, PTSD, eating disorders, personality disorders, psychosis, and substance use disorders) were listed and participants were asked to indicate whether they had ever received a diagnosis of these from a health professional.

\section{Self-harm and suicidal behaviors}

The five self-harm and suicidal behaviors measured were (1) wanting to self-harm; (2) self-harming; (3) reckless behavior that purposely puts one's life at risk; (4) suicidal thoughts; and (5) suicide attempts. Participants were asked (for each of these items) if they had engaged in the behavior in the prior 12 months, or ever in their life, that is, "Have you tried to kill yourself or made a suicide attempt?" A lifetime prevalence of these self-harm and suicidal behaviors is reported in this article to capture a longer time association between abuse and self-harm and suicidal behaviors as these may fluctuate over time. 


\section{Exposure to abuse}

Participants were asked about a range of negative experiences that are potentially associated with poor mental health as described by the focus groups that informed our questionnaire design. In this study, we report on six of those items: physical abuse outside of the family (extrafamilial physical abuse), physical abuse within the family (familial physical abuse), sexual abuse outside of the family (extrafamilial sexual abuse), sexual abuse within the family (familial sexual abuse), abuse within an intimate relationship, and other familial abuse (including emotional or verbal abuse and neglect). For each type of abuse, participants were asked if they believed that it occurred because of their trans identity, and these free-text responses were categorically coded as yes; no; partially, maybe, or sometimes; and unsure or unclear.

\section{Statistical analysis}

IBM SPSS Statistics, version 24 (IBM SPSS Statistics for Windows, version 24.0, Armonk, NY: IBM Corp., 2016), was used to calculate frequencies and develop regression models. The prevalence of each abuse type was compared by sex assigned at birth, participant age ( $<18$ vs. 18 years and older), and gender categories (male/trans male, female/trans female, and nonbinary). Comparisons were also made between participants with a binary gender identity (by grouping male/trans male and female/trans female) and those with a nonbinary gender identity. Multiple logistic regression models were used to evaluate associations between abuse and self-harm and suicidal behaviors, psychiatric diagnoses, and current psychopathology using known cutoff scores on the PHQ-A (moderately severe to severe depressive disorder) and GAD-7 (severe anxiety). Multiple linear regression models were also used to evaluate abuse and current psychopathology measured by the GAD-7 and PHQ-A as continuous variables. All reported regression outputs are adjusted for age and sex assigned at birth. All statistical models were evaluated using diagnostic testing with no major deviations in distributional assumptions detected.

\section{Results}

\section{Summary of study population}

The full survey sample comprised 859 TGD young people aged 14-25 years who were residing in Australia at the time of the survey. Demographic details of the sample are reported in Table 1. The majority of participants were assigned female at birth $(74.4 \%)$. The mean age of participants was 19.37 years $(\mathrm{SD}=3.15)$. A total of $29.7 \%$ $(n=255)$ of participants identified as trans male or male, $15 \%(n=129)$ identified as trans female or female, and $48.5 \%(n=417)$ identified as various nonbinary identities, including nonbinary trans masculine, nonbinary femme, agender, bigender, pangender, and other nonbinary identities. Further details on the gender identities of participants are reported in the study by Strauss et al. ${ }^{12}$ Approximately representative of the population of Australia, 3.7\% of participants who responded were of Aboriginal and/or Torres Strait Islander descent. ${ }^{18}$
Table 1. Sample Characteristics

\begin{tabular}{|c|c|}
\hline Characteristics & $\mathrm{n}(\%)$ \\
\hline Age, years, mean (SD) & $19.37(3.15)$ \\
\hline $\begin{array}{l}\text { Sex assigned at birth } \\
\text { Male } \\
\text { Female }\end{array}$ & $\begin{array}{l}220(25.6) \\
639(74.4)\end{array}$ \\
\hline $\begin{array}{l}\text { Gender identity } \\
\text { Male/trans male } \\
\text { Female/trans female } \\
\text { Nonbinary } \\
\text { Other }\end{array}$ & $\begin{array}{r}255(29.7) \\
129(15.0) \\
417(48.5) \\
58(6.8)\end{array}$ \\
\hline $\begin{array}{l}\text { Aboriginal and/or Torres Strait Islande } \\
\text { Respondents of total sample } \\
\text { Yes } \\
\text { No }\end{array}$ & $\begin{array}{l}\text { nt } \\
652(75.9) \\
24(3.7) \\
628(96.3)\end{array}$ \\
\hline $\begin{array}{l}\text { Psychiatric diagnoses received (lifetime } \\
\text { Depression } \\
\text { An anxiety disorder } \\
\text { Post-traumatic stress disorder } \\
\text { Eating disorder } \\
\text { A personality disorder } \\
\text { Psychosis } \\
\text { Substance use disorder }\end{array}$ & $\begin{array}{l}\text { lence) } \\
571(74.6) \\
552(72.2) \\
192(25.1) \\
174(22.7) \\
157(20.5) \\
124(16.2) \\
103(13.5)\end{array}$ \\
\hline $\begin{array}{l}\text { Self-harm and suicidal behaviors (lifetim } \\
\text { Desire to self-harm } \\
\text { Self-harming } \\
\text { Reckless behavior to purposely put } \\
\text { one's life at risk } \\
\text { Suicidal thoughts } \\
\text { Suicide attempt }\end{array}$ & $\begin{array}{l}\text { valence) } \\
639(91.3) \\
561(79.7) \\
432(62.8) \\
568(82.4) \\
333(48.1)\end{array}$ \\
\hline $\begin{array}{l}\text { Current psychopathology } \\
\text { Current severe anxiety (15+ GAD-7) } \\
\text { Current moderately severe to severe } \\
\text { depression (15+ PHQ-A) }\end{array}$ & $\begin{array}{l}267(31.6) \\
403(54.8)\end{array}$ \\
\hline
\end{tabular}

GAD-7, Generalized Anxiety Disorder 7-Item Scale; PHQ-A, Patient Health Questionnaire for Adolescents; SD, standard deviation.

\section{Prevalence of psychiatric diagnoses, self-harm and suicidal behaviors, and current psychopathology}

The lifetime prevalence of psychiatric diagnoses, selfharm and suicidal behaviors, and current psychopathology is included in Table 1 . Of note, $48.1 \%$ reported a suicide attempt, $62.8 \%$ reported engagement in reckless behavior to purposely put one's life at risk, $74.6 \%$ had been diagnosed with depression, and $72.2 \%$ had been diagnosed with an anxiety disorder. Further details on the prevalence of all mental health outcomes in this sample are reported in the study by Strauss et al. ${ }^{5,12}$

\section{Prevalence of abuse}

The prevalence of abuse experienced by the study population is summarized in Table 2. Physical abuse was more commonly perpetrated by a family member than someone external to the family ( $24.8 \%$ compared with $16.2 \%$ ). Conversely, sexual abuse was more common outside the family than within the family $(24.3 \%$ compared with $7.5 \%)$. Almost a third of participants had experienced abuse within an intimate relationship (30.9\%). Experiences of other familial abuse-including neglect and emotional or verbal abusewere reported by $57.9 \%$ of participants. 
Table 2. Abuse Prevalence by Demographic Characteristics

\begin{tabular}{|c|c|c|c|c|c|c|}
\hline & $\begin{array}{c}\text { Familial } \\
\text { physical } \\
\text { abuse, n (\%) }\end{array}$ & $\begin{array}{c}\text { Extrafamilial } \\
\text { physical } \\
\text { abuse, n (\%) }\end{array}$ & $\begin{array}{c}\text { Familial } \\
\text { sexual } \\
\text { abuse, } \mathrm{n}(\%)\end{array}$ & $\begin{array}{l}\text { Extrafamilial } \\
\text { sexual } \\
\text { abuse, n (\%) }\end{array}$ & $\begin{array}{c}\text { Other } \\
\text { familial } \\
\text { abuse, n (\%) }\end{array}$ & $\begin{array}{l}\text { Abuse within } \\
\text { an intimate } \\
\text { relationship, } \\
\mathrm{n}(\%)\end{array}$ \\
\hline Count $(\%)$ of respondents & $167(24.8)$ & $109(16.2)$ & $50(7.5)$ & $161(24.3)$ & 377 (57.9) & 205 (30.9) \\
\hline $\begin{array}{l}\text { Sex assigned at birth } \\
\text { Male } \\
\text { Female }\end{array}$ & $\begin{array}{r}48(28.9) \\
119(23.5)\end{array}$ & $\begin{array}{l}30(18.6) \\
79(15.4)\end{array}$ & $\begin{aligned} 5 & (3.0)^{*} \\
45 & (8.9)^{*}\end{aligned}$ & $\begin{array}{r}31(19.3) \\
130(25.9)\end{array}$ & $\begin{array}{r}93(58.5) \\
284(57.7)\end{array}$ & $\begin{array}{r}47(28.5) \\
158(31.7)\end{array}$ \\
\hline $\begin{array}{l}\text { Gender identity }{ }^{\mathrm{a}} \\
\text { Male/trans male } \\
\text { Female/trans female } \\
\text { Nonbinary }\end{array}$ & $\begin{array}{l}48(23.9) \\
30(30.0) \\
81(24.6)\end{array}$ & $\begin{array}{l}35(17.2) \\
18(18.6) \\
50(15.3)\end{array}$ & $\begin{aligned} 18(9.0) \\
3(3.0) \\
29(8.9)\end{aligned}$ & $\begin{array}{l}47(23.4) \\
19(19.8) \\
88(27.3)\end{array}$ & $\begin{array}{r}111(57.2) \\
60(61.9) \\
190(59.0)\end{array}$ & $\begin{array}{r}63(31.7) \\
31(31.0) \\
100(31.4)\end{array}$ \\
\hline $\begin{array}{l}\text { Gender identity group }{ }^{\mathrm{a}} \\
\text { Binary gender } \\
\text { Nonbinary gender }\end{array}$ & $\begin{array}{l}78(25.9) \\
81(24.6)\end{array}$ & $\begin{array}{l}53(17.6) \\
50(15.3)\end{array}$ & $\begin{array}{l}21(7.0) \\
29(8.9)\end{array}$ & $\begin{array}{l}66(22.2) \\
88(27.3)\end{array}$ & $\begin{array}{l}171(58.8) \\
190(59.0)\end{array}$ & $\begin{array}{r}94(31.4) \\
100(31.4)\end{array}$ \\
\hline $\begin{array}{l}\text { Age group (at survey) } \\
\text { Under } 18 \text { years } \\
18 \text { years and older }\end{array}$ & $\begin{array}{r}44(22.7) \\
123(25.7)\end{array}$ & $\begin{array}{l}27(13.9) \\
82(17.1)\end{array}$ & $\begin{array}{l}11(5.7) \\
39(8.2)\end{array}$ & $\begin{array}{r}32(17.3)^{* *} \\
129(27.0)^{* *}\end{array}$ & $\begin{array}{l}106(58.9) \\
271(57.5)\end{array}$ & $\begin{array}{r}37(20.0)^{* *} \\
168(35.1)^{* * *}\end{array}$ \\
\hline $\begin{array}{l}\text { Was the abuse attributed to trans } \\
\text { Total respondents } \\
\text { Yes } \\
\text { No } \\
\text { Partially, maybe, or sometimes } \\
\text { Unsure or unclear }\end{array}$ & $\begin{array}{c}\text { dentity? } \\
148 \\
21(14.2) \\
107(72.3) \\
11(7.4) \\
9(6.1)\end{array}$ & $\begin{aligned} & 87 \\
28 & (32.2) \\
45 & (51.7) \\
9 & (10.3) \\
5 & (5.7)\end{aligned}$ & $\begin{aligned} & 45 \\
3 & (6.7) \\
38 & (84.4) \\
& \overline{(8.9)}\end{aligned}$ & $\begin{aligned} & 141 \\
21 & (14.9) \\
100 & (70.9) \\
14 & (9.9) \\
6 & (4.3)\end{aligned}$ & $\begin{array}{c}326 \\
104(31.9) \\
140(42.9) \\
64(19.6) \\
18(5.5)\end{array}$ & $\begin{aligned} & 175 \\
& 35(20.0) \\
& 109(62.3) \\
& 21(12.0) \\
& 10(5.7)\end{aligned}$ \\
\hline
\end{tabular}

Abuse attributed to trans identity was not tested for significant differences.

$*$ Chi-square test, significant difference between the comparative sex assigned at birth groups $(p<0.05)$.

**Chi-square test, significant difference between the comparative age groups $(p<0.01)$.

"Participants with a gender identity classified as "other" were excluded from these analyses.

Sexual abuse within the family was significantly higher for those assigned female at birth (8.9\%) compared with those assigned male at birth (3.0\%). There were no other statistically significant differences in the prevalence of abuse between participants assigned male or female at birth. There were also no significant differences in prevalence when comparing by gender identity. In relation to age groups, abuse within an intimate relationship and extrafamilial sexual abuse were significantly more likely to be reported by participants aged 18 years or older (35.1\% compared with $20.0 \%$, and $27.0 \%$ compared with $17.3 \%$, respectively). Table 2 reports on whether the participant thought that the abuse occurred because of their trans identity. A third of participants $(32.2 \%)$ thought that extrafamilial physical abuse was related to their trans identity. In contrast, sexual abuse (both within and outside of the family) was rarely attributed to an individual's trans identity. For other familial abuse (including emotional or verbal abuse and neglect), the relationship with the respondent's trans identity was more mixed, with $31.9 \%$ attributing such abuse to their trans identity and $19.6 \%$ stating that the abuse may have been partially or sometimes attributed to their trans identity. Regarding abuse within an intimate relationship, $20 \%$ of participants attributed this to their trans identity and $12.0 \%$ believed that it was at least partially attributed to their identity.

\section{Associations with self-harming and suicidal behaviors}

Table 3 reports on the associations between abuse and selfharm and suicidal behaviors. All forms of abuse were associated with all five self-harm and suicidal behaviors measured, with the exception of familial sexual abuse. Familial sexual abuse was only significantly associated with two outcomes: reckless behavior to purposely put one's life at risk (odds ratio $[\mathrm{OR}]=2.680$, 95\% confidence interval $[\mathrm{CI}]=1.267$ 5.668) and suicide attempts $(\mathrm{OR}=3.009,95 \% \mathrm{CI}=1.511$ 5.995). The largest effect sizes for each of the self-harming and suicidal behaviors were as follows. Extrafamilial physical abuse had the strongest effect on the lifetime desire to selfharm $(\mathrm{OR}=12.677,95 \% \mathrm{CI}=1.724-93.206)$; however, this association had a broad confidence interval. Participants exposed to extrafamilial sexual abuse had significantly elevated odds of lifetime self-harming $(\mathrm{OR}=4.577,95 \% \mathrm{CI}=2.314$ 9.0353) compared with those without exposure. When looking at reckless behavior to purposely put one's life at risk, physical abuse within the family had the strongest effect $(\mathrm{OR}=4.048$, $95 \% \mathrm{CI}=2.563-6.396)$. A sixfold increase in the OR was estimated for extrafamilial physical abuse and reporting of suicidal thoughts $(\mathrm{OR}=6.365,95 \% \mathrm{CI}=2.281-17.761)$. For reported suicide attempts, the highest ORs were for the association with familial physical abuse $(\mathrm{OR}=4.095,95 \%$ $\mathrm{CI}=2.760-6.077)$.

\section{Associations with psychiatric diagnoses}

Two forms of abuse were strongly associated with all psychiatric diagnoses (Table 4). The largest effect sizes for each of the psychiatric diagnoses received were as follows. A threefold increase in the OR was estimated for participants who stated that they had been diagnosed with depression and had experienced familial sexual abuse $(\mathrm{OR}=3.599 ; 95 \%$ $\mathrm{CI}=1.264-10.252)$. This type of abuse was also associated 

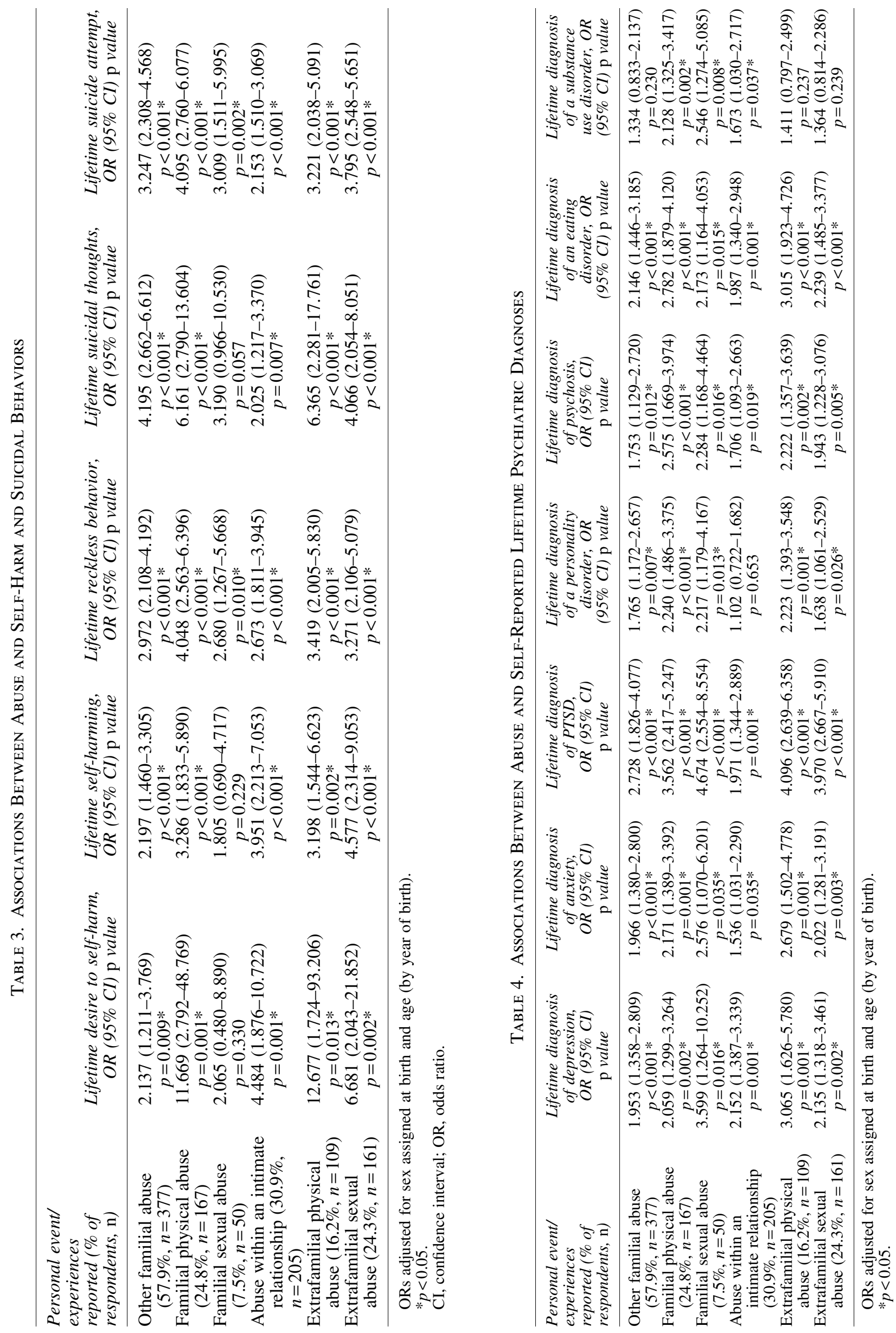
with the largest magnitude of effect for PTSD and substance use disorder $(\mathrm{OR}=4.674,95 \% \mathrm{CI}=2.554-8.554$, and $\mathrm{OR}=2.546,95 \% \mathrm{CI}=1.274-5.085$, respectively). Extrafamilial physical abuse was most strongly associated with eating disorders $(\mathrm{OR}=3.015,95 \% \mathrm{CI}=1.923-4.726)$ and anxiety disorders $(\mathrm{OR}=2.679,95 \% \mathrm{CI}=1.502-4.778)$. Both personality disorders and psychosis were most highly associated with familial physical abuse $(\mathrm{OR}=2.240,95 \%$ $\mathrm{CI}=1.486-3.375$, and $\mathrm{OR}=2.575,95 \% \mathrm{CI}=1.669-3.974$, respectively).

\section{Associations with current psychopathology}

Associations between the six forms of abuse and current psychopathology are reported in Table 5. ORs were significantly elevated for the majority of exposures to abuse, but the largest effect sizes were seen with familial sexual abuse and current severe anxiety $(\mathrm{OR}=1.985,95 \% \mathrm{CI}=1.075$ 3.666), as well as extrafamilial physical abuse and current moderately severe to severe depression $(\mathrm{OR}=2.630,95 \%$ $\mathrm{CI}=1.662-4.162)$. Linear regression models indicated that all forms of abuse were on average associated with higher symptom scores for anxiety and depression, especially familial sexual abuse and anxiety $(\beta=2.506,95 \% \mathrm{CI}=0.909$ 4.103) and other familial abuse and extrafamilial physical abuse and depression $(\beta=3.517,95 \% \quad \mathrm{CI}=2.474-4.560$; and $\beta=3.476,95 \% \mathrm{CI}=2.086-4.867$, respectively).

\section{Discussion}

This article reports on six specific forms of abuse and their associations with mental health outcomes among TGD young people. The results show that all forms of abuse were associated with poor mental health overall, although there was considerable divergence in the magnitudes of the risk estimates. This research is novel in that it provides direction for interventions to improve the mental health of TGD young people - primarily through increasing societal support and bolstering acceptance within families-by examining the associations between these six forms of abuse and mental health outcomes. Although we recognize the inherent limitations of interpreting cross-sectional data, the findings demonstrate high rates of abuse for TGD young people. The results show elevated rates of abuse occurring both within and outside of the family, as well as within intimate relationships. Almost a quarter of participants (24.3\%) reported experiencing extrafamilial sexual abuse in their lifetime. A significant difference for sexual abuse within the family was observed by sex assigned at birth, with participants assigned female at birth more likely to be exposed to this abuse, although these results should be approached with caution given the small sample size. Participants who were aged 18 years or older were more likely to report sexual abuse by someone outside of their family, and more likely to report abuse within an intimate relationship, compared with those under the age of 18 years.

The prevalence proportions for familial physical and sexual abuse $(24.8 \%$ and $7.5 \%)$ are of considerable concern. We estimated a fourfold increase in the OR for the association between familial physical abuse and lifetime suicide attempts. Although we acknowledge that many different experiences play a role in affecting the mental health of TGD young people, ${ }^{5}$ parental support (or lack thereof) is typically

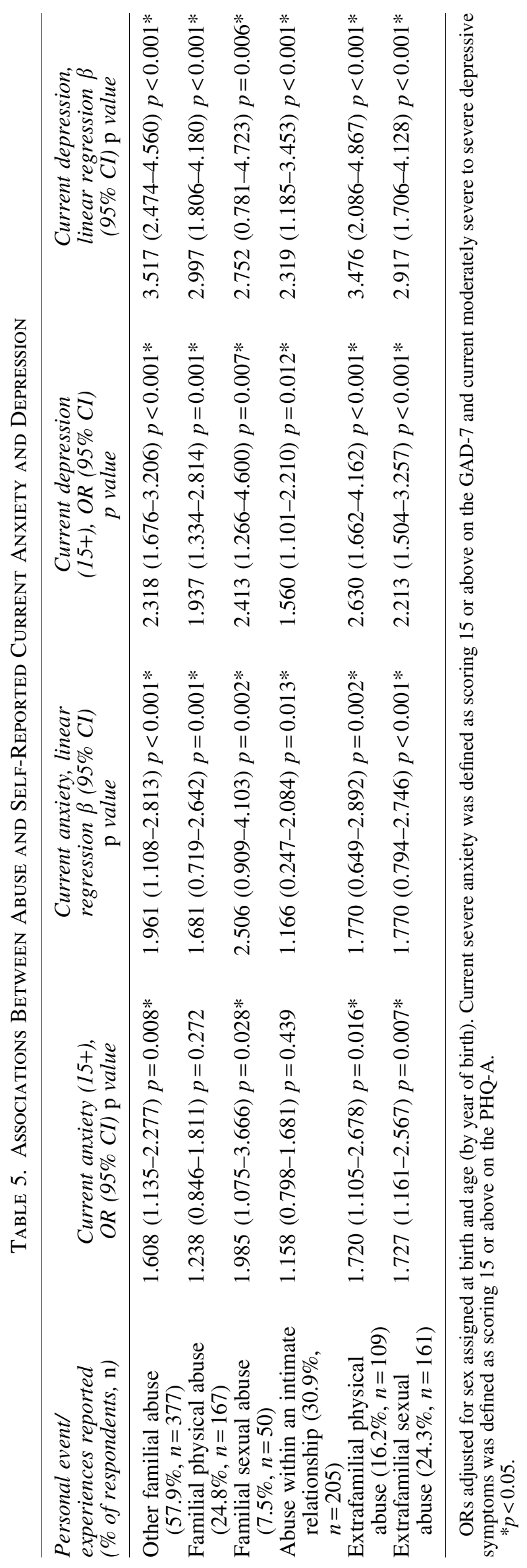


one of the vital dimensions of well-being. Research shows that TGD young people who are well supported by their parents tend to have better mental health than young people who are not supported. ${ }^{19}$ Future interventions should target this area with a focus on increasing familial acceptance and reducing violence and abuse against TGD young people within families. There are no existing evidence-based interventions specifically focused on increasing familial acceptance of TGD young people; however, an intervention has been developed for parents of TGD young people to increase their knowledge of gender diversity. ${ }^{20}$ Such interventions could be adapted, or used to inform future interventions, to specifically address acceptance and reduction of violence within the family.

Comparisons with rates of abuse within the general Australian population are difficult due to inconsistent data collection methods as well as differing definitions of abuse. In the general Australian adult population, $48 \%$ of men and $34 \%$ of women have experienced physical violence and $4.5 \%$ of men and $19 \%$ of women have experienced sexual violence since the age of 15 years. ${ }^{21}$ Although not directly comparable, intimate partner abuse appears to be more common in this sample of TGD young people (30.9\%) compared with the Australian general population, aged 18 years and older, where $23 \%$ of women and $7.8 \%$ of men have experienced violence by an intimate partner and $23 \%$ of women and $16 \%$ of men have experienced emotional abuse from an intimate partner since the age of 15 years. ${ }^{22}$ As noted, the results presented in this article indicate links between the six forms of abuse studied and self-harm, suicide, and psychiatric diagnoses. There is a well-established literature on the association between trauma/abuse and psychiatric disorders in the general population. ${ }^{23,24}$ Similar associations have been observed among transgender adults, such as between various types of intimate partner violence (sexual, physical, and psychological) and clinically significant anxiety and depression. ${ }^{9}$

It is difficult to compare our sample with young same-sex attracted and gender-questioning (SSAGQ) young people because of incongruent measures of trauma. An Australian study found that $61 \%$ of SSAGQ young people had experienced verbal abuse due to their gender identity or sexuality; $18 \%$ had experienced physical abuse due to their gender identity or sexuality; and $24 \%$ had experienced verbal and physical abuse within their family. ${ }^{25}$ A national Australian survey with gay, lesbian, bisexual, and transgender (GLBT) adults provides additional insight. GLBT adults most commonly reported being exposed to verbal abuse, with $25.5 \%$ of GLBT adults reporting experiencing this within the previous year. ${ }^{26}$ Harassment and physical violence were also reported within the prior 12 months at the time of the survey ( $15.5 \%$ and $8.7 \%$, respectively). Additional research needs to be undertaken to clarify exposure to violence within the general population, including specific types of violence enacted against people with diverse genders and sexualities, to inform policy and practice to reduce trauma. More precise and consistent data collection methods will enable more accurate comparisons across and within specific population groups.

In our study, the majority of participants did not attribute abuse to their TGD status, which is in contrast to other studies where transgender adults have commonly reported that the violence experienced was primarily because of their gender identity or expression. ${ }^{13,27}$ Despite constituting a minor- ity in our study, participants who attributed abuse to their identity need to be considered because if an individual believes that violence is perpetrated because of their identity, this can lead to internalized transphobia and the expectation of future traumatic events. ${ }^{13}$ Transgender people remain marginalized by society and face systematic discrimination. ${ }^{28}$ Violence may arise from a general lack of knowledge and understanding of transgender people as well as from fear and stigma. ${ }^{8}$ Social marginalization can also lead to exposure to situations associated with an increased risk for violence, such as homelessness, familial rejection, and poverty. ${ }^{12}$

\section{Implications of the findings}

The current findings have wide-ranging implications for clinical practice. Clinicians working with TGD young people need to be aware of the high prevalence of abuse in this population and the associations with poor mental health outcomes. Rates of PTSD were also particularly high in this sample $(25.1 \%)$, and PTSD was highly associated with all forms of abuse; therefore a trauma-informed approach to intervention should be considered. ${ }^{7,29}$ It is also important to note that trans people may not seek help from law enforcement agencies or medical staff following sexual abuse because of unfavorable past experiences with these services. ${ }^{30}$ Improved education and sensitivity among health care providers is thus imperative.

These findings also have implications for broader societal change. Violence against TGD and sexual minority populations continues to be perpetuated at a global level. A recent UN Human Rights Council Report ${ }^{31}$ argues that much of this violence and discrimination stems from structural policies and inequities that foster stigma against sexual and gender minority populations. The violence enacted against transgender populations in combination with difficulties faced accessing adequate health care has a detrimental effect on the well-being of TGD populations. ${ }^{32}$ Research on nonTGD-specific populations provides strong evidence for the long-term effect of trauma and abuse during childhood and its impact on mental health later in life. ${ }^{24}$ The results presented in this article should be considered within that context, recognizing that while these data are cross-sectional, the high rates of abuse reported are likely to have longterm impacts on mental health.

\section{Limitations}

The study design was cross-sectional and therefore causal pathways cannot be formally inferred. Moreover, all data collected were self-reported and due to the anonymous nature of the survey, they could not be verified. Longitudinal studies of TGD young people are needed to more fully investigate the temporal relationships between traumatic experiences and mental health outcomes. The majority of participants were assigned female at birth; therefore, these data may not be representative of the wider TGD population. We were limited in our analyses by the six forms of abuse that were included in the survey; further research should look specifically at timing of abuse occurrence, further subtypes of abuse, and the long-term effects on mental health outcomes. These results are limited to Australian TGD young people and may not be generalizable to populations of TGD young people in other countries. 


\section{Conclusion}

Our study explores an area of research into the well-being of TGD young people that has previously been neglected. These results add valuable insight into the mental health of TGD young people and the traumatic experiences to which they are exposed. The reported associations between traumatic experiences and adverse mental health outcomes suggest an urgent need for targeted prevention and intervention and, more broadly, enhanced societal support for TGD young people.

\section{Disclaimer}

Some data from the Trans Pathways study have previously been published, as indicated within the article, including in a report titled Trans Pathways: The mental health experiences and care pathways of trans young people. The results and statistical analyses included within this article are novel; however, some of the descriptive statistics have been reported previously.

\section{Author Disclosure Statement}

No competing financial interests exist.

\section{Funding Information}

P.S. is supported by an Australian Government Research Training Program Scholarship at The University of Western Australia. A.L. is supported by a National Health and Medical Research Council Career Development Fellowship (No. 1148793).

\section{References}

1. Clark TC, Lucassen MF, Bullen P, et al.: The health and well-being of transgender high school students: Results from the New Zealand adolescent health survey (Youth'12). J Adolesc Health 2014;55:93-99.

2. Rider GN, McMorris BJ, Gower AL, et al.: Health and care utilization of transgender and gender nonconforming youth: A population-based study. Pediatrics 2018;141:e20171683.

3. Bouman WP, Claes L, Brewin N, et al.: Transgender and anxiety: A comparative study between transgender people and the general population. Int J Transgend 2017;18:16-26.

4. Veale JF, Watson RJ, Peter T, Saewyc EM: Mental health disparities among Canadian transgender youth. J Adolesc Health 2017;60:44-49.

5. Strauss P, Cook A, Winter S, et al.: Associations between negative life experiences and the mental health of trans and gender diverse young people in Australia: Findings from Trans Pathways. Psychol Med 2019:1-10.

6. Griner SB, Vamos CA, Thompson EL, et al.: The intersection of gender identity and violence: Victimization experienced by transgender college students. J Interpers Violence 2017 [Epub ahead of print]; DOI: 10.1177/0886260517723743.

7. Mizock L, Lewis TK: Trauma in transgender populations: Risk, resilience, and clinical care. J Emot Abuse 2008;8: 335-354.

8. James SE, Herman JL, Rankin S, et al.: The Report of the 2015 U.S. Transgender Survey. Washington, DC: National Center for Transgender Equality, 2016.

9. Henry RS, Perrin PB, Coston BM, Calton JM: Intimate partner violence and mental health among transgender/gender nonconforming adults. J Interpers Violence 2018 [Epub ahead of print]; DOI: 10.1177/0886260518775148.

10. Grant JM, Mottet LA, Tanis J, et al.: Injustice at Every Turn: A Report of the National Transgender Discrimination Survey. Washington, DC: National Center for Transgender Equality and National Gay and Lesbian Task Force, 2011.

11. Smith E, Jones T, Ward R, et al.: From blues to rainbows: The mental health and well-being of gender diverse and transgender young people in Australia. Melbourne, Australia: The Australian Research Centre in Sex, Health and Society, 2014.

12. Strauss P, Cook A, Winter S, et al.: Trans Pathways: The Mental Health Experiences and Care Pathways of Trans Young People. Summary of Results. Perth, Australia: Telethon Kids Institute, 2017.

13. Testa RJ, Sciacca LM, Wang F: Effects of violence on transgender people. Prof Psychol Res Pract 2012;43:452-459.

14. Coulter RW, Blosnich JR, Bukowski LA, et al.: Differences in alcohol use and alcohol-related problems between transgender- and nontransgender-identified young adults. Drug Alcohol Depend 2015; 154:251-259.

15. Nuttbrock L, Hwahng S, Bockting W, et al.: Psychiatric impact of gender-related abuse across the life course of maleto-female transgender persons. J Sex Res 2010;47:12-23.

16. Kroenke K, Spitzer RL, Williams JB: The PHQ-9: Validity of a brief depression severity measure. J Gen Intern Med 2001;16:606-613.

17. Spitzer RL, Kroenke K, Williams JB, Löwe B: A brief measure for assessing generalized anxiety disorder: The GAD-7. Arch Intern Med 2006;166:1092-1097.

18. Australian Bureau of Statistics: Estimates and Projections, Aboriginal and Torres Strait Islander Australians, 2001 to 2026. Cat. No. 3238.0. Canberra, Australia: ABS, 2014. Available at www.abs.gov.au/ausstats/abs@.nsf/Products/ C19A0C6E4794A3FACA257CC900143A3D?opendocument Accessed September 9, 2019.

19. Travers R, Bauer G, Pyne J, et al.: Impacts of Strong Parental Support for Trans Youth. Toronto, Canada: Trans PULSE, Children's Aid Society of Toronto, and Delisle Youth Services, 2012.

20. Sharek D, McCann E, Huntley-Moore S: A mixed-methods evaluation of a gender affirmative education program for families of trans young people. J GLBT Fam Stud 2020;1: $18-31$.

21. Australian Bureau of Statistics: Personal safety, Australia, 2012. Cat. No. 4906.0 [Media release]. Canberra, Australia: ABS, 2013. Available at www.abs.gov.au/ausstats/abs@.nsf/ Latestproducts/B722D65E1AE58F4BCA257C3D000D8323? opendocument Accessed September 9, 2019.

22. Australian Bureau of Statistics: Personal Safety, Australia, 2016. Cat. No. 4906.0. Canberra, Australia: ABS, 2017. Available at www.abs.gov.au/ausstats/abs@.nsf/PrimaryMain Features/4906.0?OpenDocument Accessed September 9, 2019.

23. Lagdon S, Armour C, Stringer M: Adult experience of mental health outcomes as a result of intimate partner violence victimisation: A systematic review. Eur J Psychotraumatol 2014;5:24794.

24. Norman RE, Byambaa M, De R, et al.: The long-term health consequences of child physical abuse, emotional abuse, and neglect: A systematic review and meta-analysis. PLoS Med 2012;9:e1001349.

25. Hillier L, Jones T, Monagle M, et al.: Writing Themselves In 3 (WTi3): The Third National Study on the Sexual Health and 
Wellbeing of Same Sex Attracted and Gender Questioning Young People. Melbourne, Australia: Australian Research Centre in Sex, Health and Society, La Trobe University, 2010.

26. Leonard W, Pitts M, Mitchell A, et al.: Private Lives 2: The Second National Survey of the Health and Wellbeing of Gay, Lesbian, Bisexual and Transgender (GLBT) Australians. Melbourne, Australia: The Australian Research Centre in Sex, Health and Society, La Trobe University, 2012.

27. Clements-Nolle K, Marx R, Katz M: Attempted suicide among transgender persons: The influence of gender-based discrimination and victimization. J Homosex 2006;51:53-69.

28. Winter S, Diamond M, Green J, et al.: Transgender people: Health at the margins of society. Lancet 2016;388:390-400.

29. McCormick A, Scheyd K, Terrazas S: Trauma-informed care and LGBTQ youth: Considerations for advancing practice with youth with trauma experiences. Fam Society J Contemp Soc Serv 2018;99:160-169.

30. Walker JK: Investigating trans people's vulnerabilities to intimate partner violence/abuse. Partner Abuse 2015;6: $107-125$.
31. Madrigal-Borloz V: Report of the Independent Expert on protection against violence and discrimination based on sexual orientation and gender identity. United Nations General Assembly, 2018.

32. Winter S, Settle E, Wylie K, et al.: Synergies in health and human rights: A call to action to improve transgender health. Lancet 2016;388:318-321.

Address correspondence to:

Penelope Strauss, $M P H$

Telethon Kids Institute

Youth Mental Health

PO Box 855

West Perth, Western Australia 6872

Australia

E-mail: penelope.strauss@telethonkids.org.au 